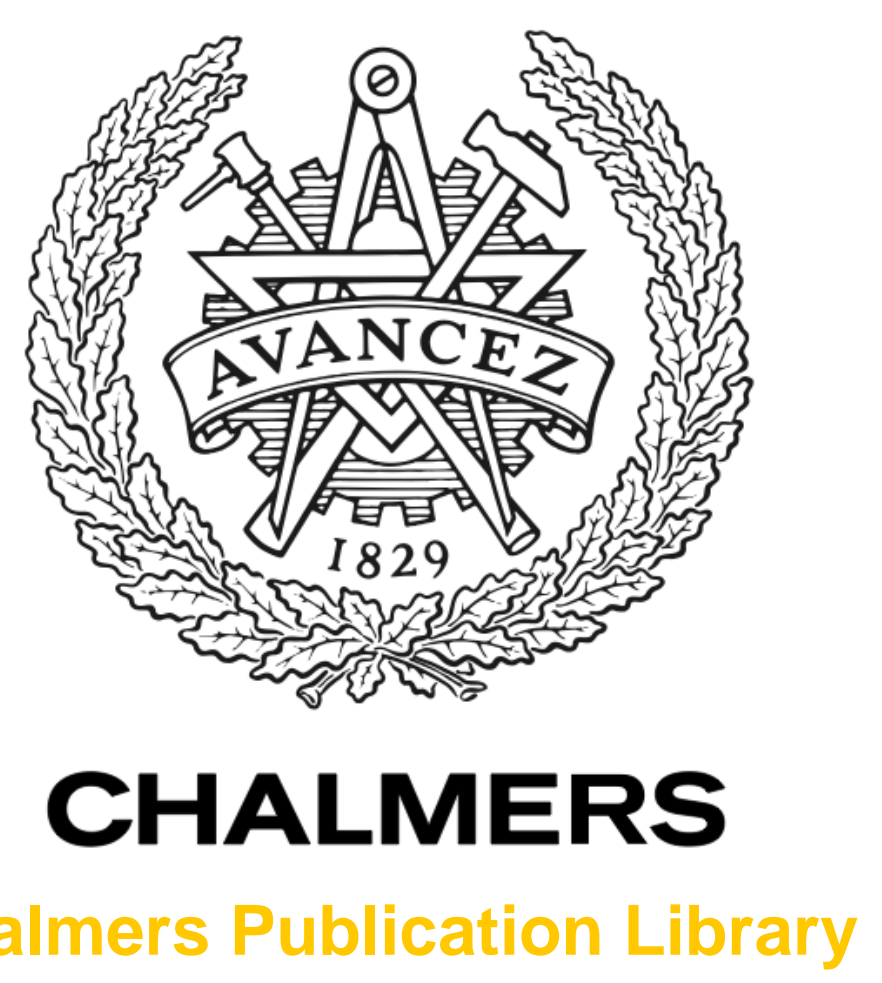

Chalmers Publication Library

\title{
Analysis of an improvement programme for MMEs
}

This document has been downloaded from Chalmers Publication Library (CPL). It is the author's version of a work that was accepted for publication in:

Journal of Manufacturing Technology Management (ISSN: 1741-038X)

Citation for the published paper:

Assarlind, M. (2015) "Analysis of an improvement programme for MMEs". Journal of Manufacturing Technology Management, vol. 26(8), pp. 1107-1125.

http://dx.doi.org/10.1108/JMTM-04-2013-0044

Downloaded from: http://publications.lib.chalmers.se/publication/214045

Notice: Changes introduced as a result of publishing processes such as copy-editing and formatting may not be reflected in this document. For a definitive version of this work, please refer to the published source. Please note that access to the published version might require a subscription.

Chalmers Publication Library (CPL) offers the possibility of retrieving research publications produced at Chalmers University of Technology. It covers all types of publications: articles, dissertations, licentiate theses, masters theses, conference papers, reports etc. Since 2006 it is the official tool for Chalmers official publication statistics. To ensure that Chalmers research results are disseminated as widely as possible, an Open Access Policy has been adopted.

The CPL service is administrated and maintained by Chalmers Library. 


\title{
Analysis of an improvement programme for MMEs
}

\author{
Marcus Assarlind*, marcus@assarlind.se \\ Division of Quality Sciences, Chalmers University of Technology
}

“This article is (C) Emerald Group Publishing and permission has been granted for this version to appear at Chalmers publication library. Emerald does not grant permission for this article to be further copied/distributed or hosted elsewhere without the express permission from Emerald Group Publishing Limited.”

\section{Purpose}

Intervention programmes can potentially aid medium-sized manufacturing companies (MMEs) in improvement work that they otherwise would not undertake. The purpose of this paper is to identify intervention programme functions that support MMEs in the adoption of operations improvements.

\section{Design/methodology/approach}

Empirical material on one programme, Production Leap, was mainly collected through 11 interviews and an internal-to-the-programme two-day workshop. This material was arranged to describe the programme's design, and subsequently compared with a theoretical framework based on the literature on operations improvements and interventions.

\section{Findings}

The interventions were divided into phases focusing on management and employees, each of which is seen as key to planning and commitment. Collaborations with labour unions and trade organisations were found to be important for gaining trust among employees and companies.

\section{Research implications}

Earlier research has identified critical factors for interventions in companies, which this paper groups into governance, involvement, and change agent approach. This paper demonstrates how a programme may or may not operationalise such factors, as well as identifies further factors.

\section{Research implications}

Practitioners and policy makers may use these findings in the design of support for MMEs, including further improvement programmes.

\section{Originality/Value}

Earlier studies on programmes have examined individual companies, while this paper analyses how a programme may be designed to aid MMEs in the adoption of systematic operations improvements. 
Keywords: Lean, interventions, quality management, SMEs, MMEs, continuous improvements, organisational learning, best practice.

Article Classification: Research paper.

\section{Introduction}

Many large companies have effective ways of improving their operations that many small and medium-sized enterprises (SMEs) commonly perceive themselves as being unable to afford (Hudson et al., 2001; Jones et al., 2005). There is also a general dearth of literature focusing on operational improvement in SMEs (Done et al., 2011; Prater and Ghosh, 2006; Ryan and Moss, 2005). This is unfortunate, since SMEs provide about two thirds of all jobs in the private sector; and in the EU and the US, for example, 99.7 to 99.8 percent of all companies are SMEs (European Commission, 2008; U.S. Census Bureau, 2015). Another problem for SME practitioners is that advice found in the literature on adoption of improvement work appears unstructured without any clear receiver or contextualisation (Sousa and Voss, 2002). Furthermore, individual SMEs are often being vastly different from each other, and results can appear too general for being relevant for practical use. It has thus been suggested that researchers should partition the SME group and discuss research contexts to greater extents (Assarlind, 2014; Sousa and Voss, 2002).

One potential solution to making it easier for SMEs to improve their operations is some sort of external intervention rather than the company's own improvement initiatives (Done et al., 2011). Such interventions, in the form of programmes, can contribute competence as well as operational structure. Recognising the lack of improvement initiatives in SMEs, governments are implementing policies to support SME development, including support for improvement programmes (Achanga et al., 2006; Karaev et al., 2007). For the most part, the literature focuses on critical factors for interventions or improvements per se (e.g., Done et al., 2011; Ghobadian and Gallear, 1997; Yusof and Aspinwall, 2000), but not on how these factors can be operationalised in programmes.

An example of an improvement programme is that of the Norwegian organisation Sintef. Neerland and Kvalfors (2000) described this programme's activities and concluded that the key initiative success factors are (1) an external instructor, (2) a company programme management group, (3) a coordinator, (4) management and employee education, (5) public management commitment, (6) making and following plans, and (7) the company's eventual ability to utilise the new knowledge and work methodology. Herron and Hicks (2008) investigated another programme, Nepa, from a knowledge transfer perspective and concluded that management commitment is the most important factor, together with the individual change agent abilities.

Another similar programme is the Swedish Production Leap (PL), which has been conducting improvement interventions in medium-sized manufacturing enterprises (MMEs) since its inception in 2007. MMEs are manufacturing companies with about 50 to 250 employees, 
which makes them an SME subgroup. PL has enjoyed public funding from three major sources and has been working with changes in about 160 companies during its first two iterations. In 2013, it was renewed for a third iteration. A number of reports have described the programme and its outcomes (e.g., Brännmark, 2010a; Brännmark et al., 2012; Medbo et al., 2013; Medbo et al., 2012). Ramböll (2009) concluded after the first iteration that the "education and coaching seems to work very well and delivers expected results" (p. 48), but that the programme missed opportunities to build long-term national structures. One of the financers commissioned a report from independent auditors (Olsson and Hellsmark, 2012), who studied the participating companies' annual accounting data and concluded that most long-term effects could not yet be determined, but that the average PL company did significantly better than those in the reference group. Based on interviews with its local branches, the labour union IF Metall reported that employee work environments were better in PL companies than in those in which other consultants aimed to implement lean operations (Bertolone, 2012). Brännmark (2010b) conducted survey studies in 24 different PL companies and identified positive changes in physical working conditions and safety, although no changes in employee stress levels. Steiber and Alänge (2013) compared seven intervention programmes, including PL, and noted that many of the investigated programmes were similar in that they provided consultancy support, as well as employee training. In that study, PL stood out for the many consultancy hours put in, the length of consultant involvement in participating companies and the large public investments in each company. Most of these studies concentrated on outcomes, and none described how a programme is designed to support an SME's improvement adoption processes or how this relates to the literature on improvement interventions.

The purpose of this paper is to identify intervention programme functions that support MMEs in the adoption of operations improvements. It does so through a comparison of the PL design with a framework based on factors from the literature on operational improvements and interventions. Thus, this paper demonstrates how a programme may operationalise such factors.

The theoretical section develops a framework about intervention-based adoption of operational improvements. The method section elaborates on material collection and analysis. The results section describes the programme and its components, and presents a stakeholders' perspective. The theoretical framework is consequently applied to the description, highlighting similarities and differences, and is followed by a section discussing findings in the context of earlier studies. The paper ends with conclusions and implications for practice and research.

\section{A theoretical framework on intervention-based operational improvements in SMEs}

A commonly cited SME characteristic is relative scarcity of resources, including for operations improvements (e.g., Bridge et al., 2003; Hudson et al., 2001; Jones et al., 2005; Rahman and Tannock, 2005). This includes money for investments, as well as improvement know-how. Medium-sized companies are naturally somewhere between small and large 
companies, and these constraints are thus less of an issue than for small companies. Mediumsized companies may both have a larger cash flow as well as some room to employ specialists (Turner et al., 2009, 2010). Nevertheless, resource constraints can still act as a mental barrier (Achanga et al., 2006; Ghobadian and Gallear, 1996). Another key characteristic for SMEs is personalised management in contrast to large companies' often institutionalised and hierarchical style (Ghobadian and Gallear, 1997; Hollander, 1967). While small companies often are owner-managed, medium-sized companies have often realised a need for more formal structures (Turner et al., 2010).

To understand operational improvement adoption programmes for MMEs, a framework is needed. While not explicitly addressing programmes, Done et al. (2011) discussed how interventions should be designed in SMEs in order to succeed both in the short and the long term, and defined an intervention as "an activity designed to introduce new practices through a series of short focused activities in the organization" (2011, p. 500). Based on a multiple case study with eight SMEs, Done et al. presented a number of propositions grouped into intervention context factors, intervention design and implementation factors, and change agent approach. This work may form a basis for understanding the Production Leap programme, but should be complemented with additional works. While the literature has a dearth of frameworks on intervention-based operational improvements in SMEs, a few address their adoption on an overall level.

First, Ghobadian and Gallear (1997) empirically compared two medium-sized companies with two large companies and presented a 10-step model for implementing quality management (QM) in SMEs: 1) recognising the need, 2) developing understanding among management, 3) establishing goals and objectives, 4) implementing plans, 5) training employees, 6) creating a systematic procedure, 7) aligning an organisation, 8) implementing the concepts, 9) monitoring implementation and 10) engaging in continuous improvements by returning to step 3 (Ghobadian and Gallear, 1997, p. 158).

Second, Yusof and Aspinwall (2000) maintained that operation improvement adoption frameworks in SMEs should neither be too prescriptive, nor tool-oriented. Instead a framework should be "systematic and easily understood, simple in structure, having clear links between the elements or steps outlined, general enough to suit different contexts, represent a road map and a planning tool for implementation, [answering] 'how to?' and not 'what is?' TQM, and implementable" (Yusof and Aspinwall, 2000, p. 33). Based in the QM area, Yusof and Aspinwall presented a framework that highlighted the need for strategy. Ideas, such as SPC, benchmarking or kaizen, should only be adopted when needed, preferably by using a sequence of planning, education, trails, review, improvement and standardisation. They further advocate a central coordinating body with all members of senior management, and representatives from supervisory and operator levels to formulate visions, measure, review and make decisions on the change work.

Third, Achanga et al. (2006) conducted a study on lean adoption success factors in which they visited ten different SMEs and conducted short follow-up interviews. In their synthesis, they identified four key factors for adopting lean manufacturing in SMEs: leadership and management (including strategy and vision); finance; skills and expertise; and organisational 
culture (in descending order of hypothesised importance). With leadership and management recognised as the most critical factors, they argued that modern management practice knowhow is often scarce in SMEs. Achanga et al. (2006, p. 468) further argued that "this factor prevents SMEs from implementing good productivity improvement strategies such as lean manufacturing”, in fear of consultant and training costs, and production halts.

In this paper, the intervention-focused framework in Done et al. (2011) is complemented by the three more general frameworks in Achanga et al. (2006), Ghobadian and Gallear (1997) and Yusof and Aspinwall (2000). These four frameworks are comprehensive, and the idea behind combining them is to capture different aspects of these different perspectives. A comparison and combination of these, resulted in 10 factors (see Table 1). The following subsections elaborate this basic structure, using additional sources. The 10 factors are grouped into governance, involvement, and change agent approach to ease the presentation and advance the new framework’s applicability for analysing improvement programmes.

Table 1: Factors extracted from Achanga et al. (2006), Done et al. (2011), Ghobadian and Gallear (1997), and Yusof and Aspinwall (2000).

\begin{tabular}{|c|c|c|c|c|c|}
\hline Group & Factor & 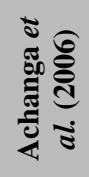 & 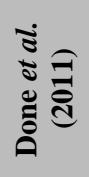 & 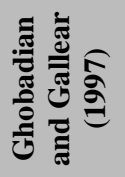 & 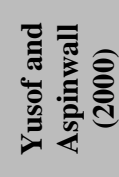 \\
\hline \multirow[t]{4}{*}{ Governance } & Tailoring to specific context & & $\mathrm{X}$ & $(\mathrm{X})$ & $\mathrm{X}$ \\
\hline & $\begin{array}{l}\begin{array}{l}\text { Developing goals for the } \\
\text { initiative }\end{array} \\
\end{array}$ & $\mathrm{X}$ & $\mathrm{X}$ & $\mathrm{X}$ & $\bar{X}$ \\
\hline & Forming a coordinating body & & & & $\mathrm{X}$ \\
\hline & $\begin{array}{l}\text { Developing KPIs aligned to } \\
\text { the goals }\end{array}$ & & $\mathrm{X}$ & & $(\mathrm{X})$ \\
\hline \multirow[t]{4}{*}{ Involvement } & $\begin{array}{lll}\begin{array}{l}\text { Involvement } \\
\text { management }\end{array} & \text { of } & \text { top } \\
\end{array}$ & $\mathrm{X}$ & $(\mathrm{X})$ & $\mathrm{X}$ & $\mathrm{X}$ \\
\hline & Showing early results & & $\mathrm{X}$ & $(\mathrm{X})$ & $\mathrm{X}$ \\
\hline & Training of employees & $(\mathrm{X})$ & & $\mathrm{X}$ & $(\mathrm{X})$ \\
\hline & Rewards and recognition & & $\mathrm{X}$ & & \\
\hline \multirow[t]{2}{*}{$\begin{array}{l}\text { Change agent } \\
\text { approach }\end{array}$} & $\begin{array}{lll}\begin{array}{l}\text { External change } \\
\text { knowledge }\end{array} & \text { agent } \\
\end{array}$ & & $\mathrm{X}$ & & \\
\hline & $\begin{array}{l}\begin{array}{l}\text { Planning for } \\
\text { activities }\end{array} \\
\end{array}$ & & $\mathrm{X}$ & & \\
\hline
\end{tabular}

Note: $\mathrm{X}$ means that the factor is discussed in the reference; whereas (X) means that the factor is briefly discussed in the reference.

The factors found are quite similar, but with different emphases. Done et al. (2011) provided the most comprehensive factor indication, and their article is the only one that substantially discusses interventions, although the factors directly tied to this aspect are still outnumbered by those not specifically addressing interventions. The frameworks by Ghobadian and Gallear (1997) and Yusof and Aspinwall (2000) focus on QM and deal with a variety of factors; however, the former advocates a normative step-by-step model, and the latter 
suggests practices that may or may not fit in different contexts. Yusof and Aspinwall (2000) were also alone with one of their key concepts: the forming of a coordinating body. Finally, Achanga et al. (2006) maintained that the focus is primarily about leadership and management. In the remainder of this section, the identified factors are elaborated upon with the aid of the views of additional authors.

\subsection{Governance}

These factors concern the design of each individual initiative and how these initiatives are steered. The literature overall seems to point towards heavy management involvement in contextualisation and on formulating and following up on goals.

\subsubsection{Tailoring to specific context}

Done et al. (2011) argued that one-size-fits-all models are as common as they are inappropriate. However, Ghobadian and Gallear (1997) maintained that the generic QM concepts are relevant for the SME context, while acknowledging that detail and adoption methods can differ. This means that improvement ideas should be feasible in SMEs, but may need to be tailored to each company.

\subsubsection{Developing goals for the initiative}

Several authors (e.g., Rahman and Tannock, 2005; Salaheldin, 2009) argued the importance of connecting an operational improvement initiative to a company's current goals, and Hodgetts et al. (1999) strongly recommended that a company's current processes should be improved rather than replaced. O'Regan et al. (2007) and Assarlind et al. (2013) showed that not all SMEs have a clear overall company strategy, but those that do outperform the others. Temtime (2003) argued that a first step in an operational improvement intervention should be to align the initiative's goals with existing company objectives. However, Ghobadian and Gallear (1997) maintained that company goals also should be developed and adjusted to fit QM practices because an articulated strategy might be lacking or might not necessarily be appropriate. In other words, goals should be developed based on existing company practices, but also inspired by new ideas from education in improvement methods.

\subsubsection{Forming a coordinating body}

Yusof and Aspinwall (2000) strongly advocated a formal coordinating body composed of most senior management and representatives from all levels of the company. This body handles overall policies, including procedures for tool selection, improvement initiative coordination, and progress review.

\subsubsection{Developing KPIs aligned to goals}

To follow, measure and guide an ongoing operational improvement initiative, several authors have suggested using key performance indices (KPIs) that are aligned to goals at all levels of the company (Done et al., 2011; Kuratko et al., 2001; van der Wiele and Brown, 1998). Bhuiyan and Baghel (2005) suggested that potential KPI levels could be strategy, groupbased problem-solving and day-to-day tasks. 


\subsection{Involvement}

Involvement factors concern the inclusion of all company levels. Management commitment is commonly cited as critical for success, followed by education for management and employees.

\subsubsection{Involvement of top management}

Management involvement is widely considered imperative to any change initiative (Beheshti and Lollar, 2003; Salaheldin, 2009; Yusof and Aspinwall, 2000). Alstrup (2000) stated that management team members often believe, at least initially, that an operational improvement initiative will affect only other employees and not themselves. In addition, Achanga et al. (2006) argued that it is imperative for management to focus on the long term, rather than postponing initiatives because of ever-arising short-term crises.

\subsubsection{Showing early results}

Yusof and Aspinwall (2000) suggested that projects within an initiative should be chosen so that tangible results can be displayed fairly quickly. Salaheldin (2009) argued that projects should preferably target strategic issues. Besides releasing resources for further improvement work, successful strategic projects would aid the initiative at all company levels. However, several authors (e.g., Done et al., 2011; Ghobadian and Gallear, 1997) have warned against unrealistic expectations, which, if not met, may discourage continued work. Struebing and Klaus (1997, p. 25) put this as, "small organisations must realise that although they should see some immediate results, the greater benefits are slower in coming."

\subsubsection{Training of employees}

Achanga et al. (2006) claimed that many SMEs have employees with low-skill levels who are not always able to master operational improvement practice technicalities, which necessitates external recruitment and training. Although Achanga et al. (2006) primarily promoted recruitment of higher-skilled individuals, most QM literature recommends training existing employees (Beheshti and Lollar, 2003; Ghobadian and Gallear, 1997; Salaheldin, 2009), which, of course, could be conflicting. It should also be mentioned that lean production initiatives have in some instances been detrimental to some companies, due to less-motivated employees (Parker, 2003).

\subsubsection{Rewards and recognition}

According to several authors (e.g., Demirbag et al., 2006; Done et al., 2011), another way to involve and motivate employees, reinforce positive effects of short-term outcomes and encourage further success is to promote rewards and recognition for positive outcomes. Rahman and Tannock (2005) also recommended rewards for good employee suggestions. However, rewards are controversial, with some arguing that monetary rewards are directly destructive for creative work because they tend to kill intrinsic motivation and teamwork (Pink, 2010; Robinson and Schroeder, 2006).

\subsection{Change agent approach}

These factors concern requirements for external change agents. The literature seems to emphasise the importance of a change agent's having both "hard" and "soft" skills, as well 
as the ability to plan for how to move forward after intervention ends, including developing competence among internal change agents.

\subsubsection{External change agent knowledge}

Many companies hire consultants to initiate operational improvement initiatives (Done et al., 2011) as they frequently lack employees trained in improvement work, including technical and managerial issues (Achanga et al., 2006), and may perceive a lack of resources for expert training (Rahman and Tannock, 2005). External consultants should be technically competent, have the "hard skills" to facilitate projects and work on many parallel activities, and also possess the "soft skills" that enable them to deal with socio-political issues, such as explaining how and why the initiative is important (Done et al., 2011). Alstrup (2000) also argued for consultants' filling the roles of communicator and coach for initiatives. Alstrup contended that managers rarely view themselves as having time for training, if they see a need at all, but that they may more easily find time and motivation for their own development if consultants assume the coordinating roles.

\subsubsection{Planning for continued activities}

An intervention is limited in time, often amounting to only a fraction of an entire adoption process. Done et al. (2011) argued that planning for continued activities and consultancy support after the intervention is finished can maintain momentum. Assarlind et al. (2013) also suggested that companies can benefit if dependence on consultants is reduced towards the end of an intervention and the company then assumes the activities internally. Herron and Hicks (2008) pointed out a correlation between capable internal change agents and intervention outcomes.

This section has summarised a combination of success factors that the literature identifies for interventions and adoption of QM and lean production in SMEs. Therefore, the ensuing framework can be used to design interventions in SMEs, or, in this case, to analyse SME improvement programmes.

\section{Method}

Although not all of the practices have been positive, such as the less than optimal focus on contributions to national structures outside the PL companies (Ramböll, 2009), the PL programme appears to be a programme worth considering. The programme has received considerable national attention, is cited to be markedly profitable in terms of return of investment for the society and is appreciated by participating companies, labour unions, business associations, and financers alike. See also section 4.4.

The case study was based on formal and informal interviews with PL staff and external stakeholders and on PL material. Semi-structured interviews (Lee, 1999) lasting 70 to 90 minutes each were conducted with six internal individuals: the programme director, programme chairman, head of consultants and three consultants. Two of these consultants had been involved in the programme from the development in 2006, and one joined in 2007. They had each been involved in about 10 interventions. The discussions began with the interviewees' views on how PL functions, what makes it work, and its potential weaknesses. 
Semi-structured interviews allow for respondents to provide their full viewpoints and thus allow for the unexpected (Flick, 2006), in contrast to structured interviews, which lack variation (Bryman and Bell, 2007).

An interview guide for PL staff was constructed to ensure the following questions were discussed: What is PL and what are its goals? What are the activities in PL interventions? Is there any difference in a PL intervention than what could have been accomplished by the individual consultants alone backed with similar financial subsidisation? Have the guidelines for intervention processes changed over time; if so, how? Is the PL methodology only applicable in its current MME context? Discussions were allowed to move fairly freely, and any potentially leading questions were left for the end of the interviews.

Furthermore, PL organises a yearly two-day event for reflection and improvements, with approximately 90 percent programme staff attendance. The author's participation in one of these events as an external observer provided unique programme insight. The event started with the programme director discussing plans for future direction, followed by lengthy and uncensored discussions in several different formats. The author observed and participated in the discussions, and the event also allowed for numerous spontaneous meetings. The material obtained allowed for triangulating (Flick, 2006) material from formal interviews.

In addition, five 60-minute telephone interviews were conducted with representatives of stakeholder organisations outside the programme organisation: a trade organisation, a labour union, and the three main financers. The trade organisation and the labour union are on the programme's board of directors because of their input, and because they can transmit their views with their respective members. Although trade and labour organisations are on the programme board, they are unlikely to be consciously biased because they are large, recognised organisations that value their reputations among their members.

The interview guide for stakeholders was constructed to discuss: How would you describe $P L$, and its role? Are you supporting the programme, and, if so, why? What has it accomplished? Has something been negative with the programme? What would need to be developed? What is critical for success of the programme? Would you like to see it receiving continued financing? Does it only work in the Nordic context?

All interviews were recorded and transcribed, and the content was summarised (Kvale and Brinkmann, 2009). This content was subsequently clustered and constructed into the case study. The results were further triangulated by the study of internal PL documents and material. The provided description of the programme aims at being rich enough to, by itself, inspire to better programmes (Creswell and Miller, 2000), while the analysis at the same time aids the reader in reaching a deeper understanding of it (Alvesson and Sandberg, 2013). This analysis was conducted by comparing this material to a theoretical framework developed in the previous section, looking for similarities and discrepancies.

The meaning of inspired by should once again be emphasised. No reader should of course blindly copy any of the practices described, but should instead look for what makes sense in their own context. For one thing, PL is a Swedish initiative. However, different cultures and 
power distances (Hofstede, 2001) may play a role in communications. Although Bessant and Caffyn (1997) established that national culture does not have any major impact on the potential of operations improvements or employee involvement, efficient communications are also established as crucial for successful operations (Choi and Liker, 1995). In countries with high power distance, such as Japan, there might be a need for special structures to facilitate communication, whereas this is not as important in countries with lower power distance (such as Sweden) (Lillrank et al., 2001). However, it should also be noted that individual company culture most likely plays a considerably larger role than national culture (Brannen, 1995).

\section{The Production Leap process}

Production Leap is a Swedish nationwide programme aimed at enhancing production processes through a lean philosophy. The initiative for PL started with the organisations KKstiftelsen (Knowledge Foundation), Tillväxtverket (Swedish Agency for Economic and Regional Growth), Vinnova (Swedish Governmental Agency for Innovation Systems), the labour union IF Metall, and the business association Teknikföretagen (The Swedish Association of Engineering Industries). These five actors have had representatives on the PL board, and the first three have also acted as financers of the programme.

The programme seeks to spread knowledge throughout the company and to engage employees to take on leading change work roles. One consultant stated, "It is all about working smarter, not harder," and continues to argue that without systems in place to ensure proper, proportional responses to problems, individual issues steal employees' attention and drain resources. In short, a PL intervention in a company consists of education and a number of pilot projects. The programme direction emphasises focusing on four stakeholders of the companies: the owners, the employees, the customers, and society.

The first iteration of PL was initiated in 2007 and included 60 companies before its conclusion in 2010. The sponsors deemed the programme a success and launched a second iteration in 2011 (which involved 100 companies) and a third in 2013. Recognising the large differences between small and medium-sized companies, PL only targets the latter (those with roughly 30 to 250 employees) in the manufacturing sector.

\subsection{Initiating an intervention}

To market PL, "insight seminars" are held with partners (universities, company networks, and others) to provide a general programme overview. Interested participants can then apply to be a part of the programme. Today, after many completed interventions, interviewees regard word-of-mouth marketing as more important than seminars.

Companies applying for programme participation are reviewed using formal criteria such as size and business sector, and are visited to evaluate the chances for successful interventions. According to the head evaluator, the main criterion is whether owners and management seem amenable to allowing everyone to be involved and to employee empowerment. Companies that are accepted are assigned a main and an assisting consultant (the so called "coaches"). For each company, the consultants' time budget is roughly 350 total hours, with most of this 
time spent on site. Although the main consultants have the larger responsibility for the interventions, assistant consultants provide support and ensure benchmarking and harmonisation between the interventions. This function is facilitated by frequent meetings among the assistant consultants participating in simultaneous interventions.

One of the first actions of a participating company is to form a Lean Steering Group, consisting of the management and additional key stakeholders, such as labour union representatives. Some companies choose to include more people, which results in a diversity of steering group sizes. If the group becomes too large, it usually is made a reference committee and an operative work group emerges. The steering group includes a companyappointed Lean Coordinator, who joins, at least, one other person to attend a 7.5-credit university course in lean production.

\subsection{Phase 1 - Developing strategy}

Phase 1 of a PL intervention normally constitutes the first three months and consists of five different workshops, each a full day with "homework" before the next session. For the most part, the main consultant leads these relatively standardised workshops (see Table 2), which the Lean Steering Group attends. Interviewees emphasised the importance of the homework assignments for employees to continue to reflect and work in between the consultant visits.

The main idea of phase 1 is to create a common understanding of basic values for the company and the improvement initiative. During PL's first iteration, the focus was on "doing things" in the companies, with phase 1 often being finished quite quickly. However, individuals in many companies rarely shared a common sense of direction; or, as one consultant said, "While things were done, they were not always in line with what the company needed." The same consultant remarked that the Steering Group often failed to articulate a sense of direction initially other than that the company should make money. Therefore, creating common understanding within the Steering Group is now considered more important than accomplishing practical improvements that can potentially be misdirected. These issues are targeted in the Vision and Strategy workshop: "We start in any existing business and scrutinise these; any vague formulations such as "we aim to enhance our productivity' are discussed in terms of how to reach these goals and the principles that should support that.” Phase 1 is considered crucial, and depending on the progress the main consultant may allow it to go on for more than the three months (up to six months are not that uncommon), with additional workshops and room for discussions.

Prior to the workshops, many individuals or the entire company may be largely unaware of operational improvement ideas. The programme director said that most companies, "do not know of all the resources that just disappear; that they with fewer operators and less space still can produce more."

Based on the action plan compiled during the final workshop, the Steering Group is able to "mount the barricades" and announce the plans and intentions to the company. One common way to support this process is to include most employees in a lean game. One consultant especially emphasised the importance of the Steering Group members' modelling for other employees how to embrace new ideas and practices. 
Table 2: Content and "homework" for each of the five phase 1 workshops.

\begin{tabular}{|c|c|c|}
\hline Workshop & Content & Homework \\
\hline $\begin{array}{l}\text { 1. Lean } \\
\text { Introduction }\end{array}$ & $\begin{array}{l}\text { Introduction and a "lean game,” an } \\
\text { activity that often uses Lego pieces to } \\
\text { demonstrate how practices such as flow, } \\
\text { pull and good communication can } \\
\text { enhance a production line. }\end{array}$ & $\begin{array}{l}\text { Create a visual lean } \\
\text { journey board to express } \\
\text { what the lean initiative } \\
\text { is to all employees; for } \\
\text { example, the } \\
\text { participants and the } \\
\text { planned activities. }\end{array}$ \\
\hline $\begin{array}{l}\text { 2.Organisational } \\
\text { Issues }\end{array}$ & $\begin{array}{l}\text { Leadership, motivation, and respect for } \\
\text { individuals. }\end{array}$ & $\begin{array}{l}\text { Begin considering an } \\
\text { appropriate pilot area } \\
\text { for improvement work. }\end{array}$ \\
\hline $\begin{array}{l}\text { 3. Value Stream } \\
\text { Mapping }\end{array}$ & $\begin{array}{l}\text { The group observes one flow and } \\
\text { identifies parts that are or are not value } \\
\text { adding. A flow may run from receiving } \\
\text { an order to the start of production, from } \\
\text { start of production to end of production, } \\
\text { or from end of production to delivery. } \\
\text { Usually, flow is performed in the } \\
\text { manufacturing area. }\end{array}$ & $\begin{array}{l}\text { Where does the } \\
\text { company want to go, } \\
\text { and what does it want to } \\
\text { accomplish with the PL } \\
\text { initiative? How KPIs } \\
\text { could/should be used to } \\
\text { enhance the work. }\end{array}$ \\
\hline $\begin{array}{l}\text { 4. Vision \& } \\
\text { Strategy }\end{array}$ & $\begin{array}{l}\text { Considers such questions as "How does } \\
\text { the company 'think'?” and "Where does } \\
\text { it want to go?” This workshop focuses } \\
\text { on why the company should be good in } \\
\text { certain areas, such as making high- } \\
\text { quality products, and connects that } \\
\text { discussion to company goals. The } \\
\text { starting points are any existing business } \\
\text { and quality policies. }\end{array}$ & $\begin{array}{l}\text { Summarise and } \\
\text { condense the workshop } \\
\text { content into a document, } \\
\text { often a pamphlet, which } \\
\text { states the company's } \\
\text { core principles. }\end{array}$ \\
\hline $\begin{array}{l}\text { 5. Summary \& } \\
\text { Pilot Plan }\end{array}$ & $\begin{array}{l}\text { Ideas and discussions of previous } \\
\text { workshops are compiled, and the } \\
\text { pamphlet is refined. The group decides } \\
\text { on an action plan and details the area to } \\
\text { be piloted first. }\end{array}$ & \\
\hline
\end{tabular}

\subsection{Phase 2 - Pilot areas}

From the start of phase 2, the Steering Group is less active and serves more as a reference group to promote the initiative throughout the company and to support various change activities. During this phase Steering Group activities are largely limited to monthly evaluation meetings. Phase 2 starts with work in the pilot area that was identified during the previous workshops, often chosen because the area is causing a bottleneck or is critical in some other way. With support from the Lean Coordinator and consultants, all employees 
from the pilot area participate in a workshop to establish a common understanding regarding the company's goals for this particular process step. Participants learn both general lean principles and methods relevant to their specific improvement areas. These areas of education are identified both in phase 1 with the Steering Group and with the group. Examples of such workshops are value-stream mapping, standardised ways of working, machine downtime reduction, and " $5 S$ " (sort, straighten, shine, standardise and sustain). The workshops utilise a common standardised PL pool of "tool knowledge," with educational and support material for the various tools. While the knowledge pool is standardised, the selection of the tools and workshops is not. For example, if the pilot group, consultants and coordinator decide that the root causes are that people often need to search for tools, "5S" might be appropriate.

Initially, consultants support the process by identifying problems and helping the group to understand them. One consultant emphasised the role of tools by saying, "The smorgasbord of useful tools is just that, nothing else. Lean is a mind-set, not the use of certain tools." Instead, one consultant said the core was, "the principles that are developed together with the Steering Group, and conveyed to the whole company [...] Coaches are not supposed to make themselves indispensable, but to integrate the principles in the companies and to aid them in aiding themselves."

A few weeks after the first pilot project is initiated, additional projects in other areas follow similar educational and change processes. With each new pilot group, individuals from the Steering Group should be included to keep them operationally active. The number of pilot areas started can vary, but two to five are normal. Often, pilot groups become permanent improvement groups.

As each new area is started, the Lean Coordinator is expected to shoulder more responsibilities. All interviewed consultants emphasised this individual, because, as one said, "Things must happen in between my visits, which are only about every fortnight" and the Lean Coordinator is the primary engine. Another consultant highlighted that consultants generally dominate the intervention, and there is a risk that the coordinator may not be perceived as ready to lead the lean initiative; however, the programme does not address this potential problem.

Phase 2 ends approximately 18 months after the start of phase 1, and PL representatives leave the company having initiated the internal drive within the company. The interviewed consultants were quite humble about the results of their interventions: "During these 18 months, the companies have merely started to gain more insight in lean thinking, and lean work has just begun." Consultants are sometimes rehired to check back on the company every quarter. However, such initiatives are outside the PL programme, and are made solely at a company's initiative.

\subsection{Views on Production Leap}

Owing to the programme's external financers, each company must carry only roughly half of the affiliated costs. One consultant said it would be impossible to run the programme without these contributions, especially for smaller SMEs. However, some of the interviewees, including consultants, the programme chair and external stakeholders, believed 
the cost issue was mainly psychological: "Several companies have since commented that this [starting with continuous improvements in operations] is something they, in retrospect, should have done anyway, but due to lack of knowledge would probably not have done if not for the Production Leap programme.”

When asked about success factors, the programme director viewed ties to the labour union as central. The programme director said the perspectives of top management and shop-floor employees were equally important, and it was critical for the programme to focus on both top-down and bottom-up. The interviewees seemed to agree that the programme was developed from a Nordic context, which implies that historically powerful unions and employers share the notion that companies' success correlates with good working conditions and wages. In this case, one of the nation's largest labour unions (IF Metall) put its "stamp of approval" on the programme, telling employees that the outcomes were likely to benefit both the company and employees. In addition, the Nordic context implies that employees are generally relatively empowered and used to taking the initiative. Programme management and stakeholders reiterated on several occasions that the programme was developed towards these Swedish conditions and having empowered employees who "dare speak their mind to their bosses" is a prerequisite.

There were five official stakeholders: the three financers (KK-stiftelsen, Tillväxtverket, and Vinnova), the labour union IF Metall, and the business association Teknikföretagen, all of which were contacted for their opinions on the programme's value. One stated, "Without these interventions, some of these companies would likely not have survived." When asked about the economic benefits, one stakeholder said, "One of the participating companies recently decided to move back production from China. This alone would motivate the full investment [in the programme] in terms of return of investment to society." A third added, "Lean is a hygiene factor for continued survival." All stakeholders described the scope of PL to be the key factor in their success: "When some [other] 'lean consultants' enter companies without considering the larger picture and introduce tools, perhaps running some projects, and then leave without effecting any changes in company culture, they may do more harm than good." A couple of financers also emphasised benefits other than investments for society. Because many PL parties are academic or research institutes, there is the potential for increased future cooperation on research and organisational development among companies and universities. This possibility was mentioned as an important additional reason (beyond the main reason of strengthening operational competencies among Swedish SMEs) for the involvement of KK-stiftelsen, who aim to support research and competence development. None of the interviewed stakeholders volunteered any negative aspects. In response to the direct question, they suggested there was a reliance on individual consultant skills and that some consultants were better at effecting change than others because the consultants possess varying experience levels. 


\section{Analysis}

This section compares the case study results with the conceptual framework, noting similarities and discrepancies and providing practical case examples. It is organised according to the three groups of factors from the literature synthesis.

\subsection{Governance}

Interviewed staff described the first iterations of PL as fairly rigid, with a short planning period and application of the same tools in most companies. They stated that the programme has since more emphasised planning, structured around a coordinating body. This coordinating body was indicated as a key factor in the programme, but has not been heavily emphasised in literature, with the exception of Yusof and Aspinwall (2000). In this phase, the Steering Group decided on goals the company should work towards, based on their new understanding of operational practices, and thus integrating both the company's views (as suggested by Temtime, 2003) and improvement practices, as suggested by Ghobadian and Gallear (1997). With a larger emphasis on company goals, PL has moved away from a onesize-fits-all application of tools, which Done et al. (2011) discouraged, to having a box from which tools can be selected as needed. In phase two, the focus is no longer on the Steering Group's work, but the group still convenes to follow-up, based on KPIs (Kuratko et al., 2001). The Steering Group is thus key to initiative governance.

\subsection{Involvement}

Most people involved in the PL programme seemed to agree that a key factor was the focus on both management and employees (Beheshti and Lollar, 2003; Yusof and Aspinwall, 2000). Interviewees said that top managers are quite often surprised to discover they are supposed to be active (Alstrup, 2000), and this realisation is not established until after several workshops have been completed.

PL operationalises management of potentially unrealistic results expectations (Done et al., 2011; Ghobadian and Gallear, 1997) by clearly stating that the first six months are for planning alone. This period provides time to identify strategic improvement areas so that the first projects are more likely to be successful, which demonstrates the new ideas' potency (see also Salaheldin [2009]; Yusof and Aspinwall [2000]).

Within PL, emphasis is on training existing employees in contrast to external recruitment, something that is evident both in the internal recruitment of the Lean Coordinator and in the comprehensive employee training during the start-up and running of the pilot areas. This approach has been recommended by several authors, such as Hodgetts et al. (1999), Kumar and Antony (2008), and Rahman and Tannock (2005). The PL programme does not discuss external recruiting, but it could nevertheless potentially be beneficial because some technicalities might be difficult to absorb without education (Achanga et al., 2006).

Hodgetts et al. (1999) and Kumar and Antony (2008) advocated financial rewards, which Pink (2010) and Robinson and Schroeder (2006) strongly discouraged. Interviewees said that PL has no guidelines on this issue; therefore, this study cannot contribute to the rewards and recognitions debate. 
In summary, PL focuses on involving management during phase 1, and employees during phase 2.

\subsection{Change agent approach}

Done et al. (2011) proposed planning for continued activities after interventions. None of the interviewed PL consultants viewed the 18-month interventions as the end of operational improvement initiatives. The idea is for each company to be able to continue on its own after PL ceases its formal involvement. More than one interviewee phrased this to mean that increased and continual benefits should come to companies that take initiative and continue to improve, similar to findings in Assarlind et al. (2013). However, PL completely halts all work with the companies after the interventions.

The Lean Coordinator is meant to take increasingly more responsibility during interventions as Done et al. (2011) suggested, but interviewed consultants testified that the abilities of Lean Coordinators vary considerably. In cases where the Lean Coordinators do not grow into their roles, consultants keep more responsibilities; in these cases, interviewees worried most about the outcomes (compare with Herron and Hicks [2008]). On the other hand, they also said that when revisiting some of these companies, they were surprised about how well the company responded. Since the PL programme ceases to work with companies after the 18-month intervention, it is hard to say anything definite about what happens after interventions. The importance of the internal change agents indicates that the PL programme may need to incorporate a better process of ensuring their post-intervention presence.

PL thus plans for continued activities by building internal competence during the interventions, but does not support companies after the intervention.

\section{Discussion and implications}

This study supports the notion by Ghobadian and Gallear (1997) that basic improvement practices are widely applicable, but that the approach may be more difficult in SMEs. During the staff event five years after the start of the PL programme, which the author attended, there was little talk about technical issues. The main discussions concerned how to improve communication, both in steering groups and in pilot groups. Done et al. (2011) discussed both technical and communicative skills, which suggests that in the PL programme the former were easier to accomplish than the latter and/or that communication issues were overlooked during the programme's early development. Especially interesting was that the programme focused on "doing" during the first iteration, and has now moved towards planning and involving the management, essentially shifting attention from phase 2 to phase 1. While this does not invalidate technical concerns, it does suggest that MME intervention programmes should direct substantial attention to the softer aspects.

Overall, practices found in PL seem similar to those Neerland and Kvalfors (2000) discussed regarding the Sintef programme: (1) external instructors in the coaches, (2) programme management group in the Steering Group, (3) a person with dedicated time in the Lean Coordinator, (4) education for both management and employees, (5) continued involvement of management, (6) extensive planning manifested in phase 1 and (7) the desire for the 
company to continue to evolve. Of particular notice is the management group, whose importance otherwise is emphasised only by Yusof and Aspinwall (2000). However, there are additional distinguishing PL programme features compared with Sintef, particularly regarding its structure outside of direct interventions. Especially noticeable are the long-term contractual commitment, the relations to stakeholders (for example, labour unions and trade organisations) and the continued development and learning of the programme itself.

For the first point, study participants repeatedly suggested that a critical success aspect of the PL method is that companies sign up for the long haul - at least 18 months. This routine of signing contracts was also identified as uncommon when compared with other programmes (Steiber and Alänge [2013] found a similar emphasis only in the UK-based Centrim). As with the argument Struebing and Klaus (1997) presented, PL emphasises that time must be taken for planning without rushing for immediate results. Therefore, this forced planning period may make it easier to use the intervention period to build further improvement capacity, rather than to implement quick fixes and mere introductions of methods and tools. This planning phase is also seen as a major contributor to building management commitment, which Herron and Hicks (2008), among others, identified as the main critical factor. However, this consultant commitment comes at a cost; Steiber and Alänge (2013) noted that PL is particularly long-term and intense in consultancy support and also costly in terms of external financing. Then again, the financers interviewed maintained that the public investments were particularly well invested when considering the return to society.

For the second point, the close ties to the trade organisation and the labour union ensure that the programme incorporates these perspectives. Assuming these organisations are happy with the outcome, the trade organisation can consequently endorse the PL programme to other companies as being beneficial and not just a waste of time and resources, and the labour union can endorse it to employees. Other studies have shown that companies that are working with lean production may actually suffer decreased productivity because of less-motivated employees (Parker, 2003). In those instances, the labour union can reassure people who may have heard about "lean being mean" that the change programme is not threatening, but can improve working conditions and the company's survival probability (see also Bertolone, 2012).

For the third point, the structure makes it possible to improve and develop the programme itself. The PL programme's yearly meetings of all staff and more regular meetings of assistant consultants improve the shared methodology. The programme is now said to be similar in structures, but quite different in execution, compared to when it first started. The stakeholder interviews also emphasised considering other programme features beyond direct interventions, for example that such arrangements also ease financing, and provide research opportunities.

The PL study lends further support to the feasibility of more guiding frameworks, such as that of Yusof and Aspinwall (2000), rather than more prescriptive ones, such as that of Ghobadian and Gallear (1997). While the PL programme started in a prescriptive mode with almost a set number of sequential tools to apply, it has since emphasised the softer aspects, and only using the toolbox as a smorgasbord to pick from when needed. 
Considering the importance of continued activities (e.g., Done et al., 2011), it could be argued that the PL organisation should develop better PL company support procedures, even after the individual 18-month interventions. For example, gatherings in which "graduated" PL companies could meet to exchange experiences from the post-intervention period could be beneficial and may help build "further national structures," as Ramböll (2009) sought ${ }^{1}$. Also, given the importance of the internal change agent (Herron and Hicks, 2008), the development of the Lean Coordinator should probably be given more attention.

\section{Conclusions}

Not all MMEs know enough to independently start an operational improvement initiative. Instead, they may be more successful in departing on such journey through interventions, especially if partially sponsored externally. The purpose of this paper was to identify intervention programme functions that support MMEs in the adoption of operations improvements. By doing this, the paper expands on earlier intervention-focused research on operations improvements in SMEs, such as that of Done et al. (2011).

This paper showed how PL operationalises advice and critical factors found in earlier literature, which was grouped in governance, involvement, and change agent approach. For example, PL emphasises education and involvement of all levels of employees and management. The involvement of management is mainly accomplished by creating a company coordinating body, whose importance is emphasised in this case, as well as in the programme described by Neerland and Kvalfors (2000). This involvement is further reinforced by the lengthy planning period, which also aids in realising mechanisms for longterm improvement, rather than quick fixes. In fact, this lengthy planning period is made possible by the contractual long-term commitment a participating company makes, which is one of the three critical factors identified in this study that are otherwise not present in the literature. The second one is the close ties to the labour union and trade organisations to broker relations with employees and companies; the third is the continuous improvement of the programme itself.

\subsection{Limitations and further studies}

This study covers only the perspective of the PL intervention programme and its official stakeholders and does not involve empirical material from participating companies, since the latter view is discussed in earlier studies (e.g., Brännmark, 2010b; Olsson and Hellsmark, 2012).

Herron and Hicks (2008) identified in their study on the Nepa programme that developing individual internal change agents can have considerable impact on the intervention outcomes. PL has a standardised process of workshops, but it stands to reason that individual external change agents (the PL consultants) are also likely to impact the process outcomes. For

\footnotetext{
${ }^{1}$ Upon reading the finished manuscript for this article, the PL programme director wished to add that they have been progressively more active in working with "further national structures" since 2010 and in particular during 2015 (the latter being after the data collection for this article).
} 
example, some consultants may potentially follow the PL methodology more closely, or some may consistently perform better than others. It would be interesting to investigate the extent of such differences and the potential effects and causes.

Furthermore, the PL programme was developed for the Nordic context, with employees generally used to participation and being able to voice their opinions. Lillrank et al. (2001) suggested that countries with higher power distances (Hofstede, 2001) might need more attention to communication structures. Thus, additional investigations from an international perspective would be interesting.

Finally, while the SME-centred research fortunately is growing, there is now a need for studies that differentiate within this vast group (Assarlind, 2014; Sousa and Voss, 2002). This study, which discusses the more narrow MME perspective, is one step in such direction, but it would be beneficial if more should follow.

\section{Acknowledgements}

The author wishes to express his deepest gratitude to all interviewees, who enthusiastically shared their experiences for the common good, and in particular Clas Mellby, who kindly facilitated access to interviewees and meetings. Many thanks also directed to the skilful anonymous reviewers who helped improve the quality of this paper.

\section{References}

Achanga, P., Shehab, E., Roy, R. and Nelder, G. (2006), "Critical success factors for lean implementation within SMEs”, Journal of Manufacturing Technology Management, Vol. 17 No. 4, pp. 460-471.

Alstrup, L. (2000), “Coaching continuous improvement in small enterprises”, Integrated Manufacturing Systems, Vol. 11 No. 3, pp. 165-170.

Alvesson, M. and Sandberg, J. (2013), Constructing Research Questions: Doing Interesting Research, Sage Publications, London.

Assarlind, M. (2014). Adoption of Quality Management in SMEs, Thesis for the degree of $\mathrm{PhD}$, Chalmers University of Technology, Gothenburg.

Assarlind, M., Eriksson, H., Gremyr, I. and Jakobsson, T. (2013), "Adopting new ways of working in SMEs: Findings from interventions in 12 european companies”, Total Quality Management \& Business Excellence, Vol. 24 No. 8, pp. 945-958.

Beheshti, H. M. and Lollar, J. G. (2003), “An empirical study of US SMEs using TQM”, Total Quality Management \& Business Excellence, Vol. 14 No. 8, pp. 839-847.

Bertolone, T. T., (2012), “Uppföljning hos IF Metallklubbar på Produktionslyftsföretag”, I. Metall, Stockholm.

Bessant, J. and Caffyn, S. (1997), "High-involvement innovation through continuous improvement”, International Journal of Technology Management, Vol. 14 No. 1, pp. 7-28.

Bhuiyan, N. and Baghel, A. (2005), “An overview of continuous improvement: From the past to the present”, Management Decision, Vol. 43 No. 5, pp. 761-771. 
Brannen, M. Y. (1995). "Does culture matter? Negotiating a complementary culture to support technological innovation”. In J. K. Liker, J. E. Ettlie \& J. C. Campbell (Eds.), Engineered in Japan: Japanese Technology-Management practices, Oxford University Press, New York, pp. 321-345.

Bridge, S., O'Neill, K. and Cromie, S. (2003), Understanding Enterprise, Entrepreneurship, and Small Business, Palgrave Macmillan, New York.

Bryman, A. and Bell, E. (2007), Business Research Methods, Oxford University Press, Oxford.

Brännmark, M., (2010a), "Implementering av Lean i medelstora företag - En lärande utvärdering om hållbar utveckling”, Linköping_University, Linköping.

Brännmark, M., (2010b), "Lean working environments - An empirical study of 24 Companies implementing lean”, Linköping_University, Linköping.

Brännmark, M., Langstrand, J., Johansson, S., Halvarsson, A., Abrahamsson, L. and Winkel, J. (2012), "Researching Lean: methodological implications of loose definitions", Quality Innovation Prosperity, Vol. 16 No. 2, pp. 35-48.

Choi, T. Y. and Liker, J. K. (1995), "Bringing Japanese continuous improvement approaches to U.S. manufacturing: The roles of process orientation and communications", Decision Sciences, Vol. 26 No. 5, pp. 589-620.

Creswell, J. W. and Miller, D. L. (2000), "Determining Validity in Qualitative Inquiry", Theory Into Practice, Vol. 39 No. 3, pp. 124-130.

Demirbag, M., Tatoglu, E., Tekinkus, M. and Zaim, S. (2006), "An analysis of the relationship between TQM implementation and organizational performance: Evidence from Turkish SMEs”, Journal of Manufacturing Technology Management, Vol. 17 No. 6, pp. 829-847.

Done, A., Voss, C. and Rytter, N. G. (2011), "Best practice interventions: Short-term impact and long-term outcomes”, Journal of Operations Management, Vol. 29 No. 5, pp. 500-513.

European Commission, (2008), "Putting small businesses first", available at: http://ec.europa.eu/enterprise/entrepreneurship/docs/sme_pack_en_2008_full.pdf (accessed 6 May 2009).

Flick, U. (2006), An Introduction to Qualitative Research, Sage Publications, London.

Ghobadian, A. and Gallear, D. N. (1996), "Total quality management in SMEs", Omega, Vol. 24 No. 1, pp. 83-106.

Ghobadian, A. and Gallear, D. N. (1997), “TQM and organization size”, International Journal of Operations \& Production Management, Vol. 17 No. 2, pp. 121-163.

Herron, C. and Hicks, C. (2008), "The transfer of selected lean manufacturing techniques from Japanese automotive manufacturing into general manufacturing (UK) through change agents”, Robotics and Computer-Integrated Manufacturing, Vol. 24 No. 4, pp. 524-531.

Hodgetts, R. M., Kuratko, D. F. and Hornsby, J. S. (1999), "Quality implementation in small business: Perspectives from the Baldridge Award winners", S.A.M. Advanced Management Journal, Vol. 64 No. 1, pp. 37-47.

Hofstede, G. H. (2001), Culture's Consequences: Comparing Values, Behaviors, Institutions and Organizations Across Nations (2nd ed.), Sage Publications, Thousand Oaks, CA.

Hollander, E. D. (1967), The Future of Small Business, Frederick A Praeger, New York. 
Hudson, M., Smart, A. and Bourne, M. (2001), "Theory and practice in SME performance measurement systems", International Journal of Operations \& Production Management, Vol. 21 No. 8, pp. 1096-1115.

Jones, S. C., Knotts, T. L. and Brown, K. L. (2005), "Selected quality practices of small manufacturers”, The Quality Management Journal, Vol. 12, pp. 41-53.

Karaev, A., Koh, S. C. L. and Szamosi, L. T. (2007), "The cluster approach and SME competitiveness: a review”, Journal of Manufacturing Technology Management, Vol. 18 No. 7, pp. 818-835.

Kumar, M. and Antony, J. (2008), “Comparing the quality management practices in UK SMEs”, Industrial Management \& Data Systems, Vol. 108 No. 9, pp. 1153-1166.

Kuratko, D. F., Goodale, J. C. and Hornsby, J. S. (2001), “Quality practices for a competitive advantage in smaller firms”, Journal of Small Business Management, Vol. 39 No. 4, pp. 293-311.

Kvale, S. and Brinkmann, S. (2009), Den Kvalitativa Forskningsintervjun (S.-E. Torhell, Trans. 2nd ed.), Studentlitteratur, Lund.

Lee, T. W. (1999), Using Qualitative Methods in Organizational Research, Sage Publications, Thousand Oaks, CA.

Lillrank, P., Shani, A. B. R. and Lindberg, P. (2001), "Continuous improvement: Exploring alternative organizational designs”, Total Quality Management, Vol. 12 No. 1, pp. 41-55.

Medbo, L., Carlsson, D., Olsson, P., Wänström, C. and Langbeck, B. (2013). “Trajectories for successful lean transformations: Case studies of four Swedish SMEs”. Paper presented at the 2nd International Scientific Conference on Lean Technologies: Lean Tech'13, September 5-6. Belgrade.

Medbo, L., Carlsson, D., Stenvall, B. and Mellby, C. (2012). "Implementation of Lean in SME, experiences from a Swedish national program”. Paper presented at the 1st International Scientific Conference on Lean Technologies: Lean Tech'12, September 13-14. Novi Sad.

Neerland, H. and Kvalfors, T. (2000), "Practical experience with quality improvement in small companies”, Integrated Manufacturing Systems, Vol. 11 No. 3, pp. 156-164.

O'Regan, N., Sims, M. A. and Gallear, D. N. (2007), "Leaders, loungers, laggards: The strategic-planning-environment- performance relationship re-visited in manufacturing SMEs”, Journal of Manufacturing Technology Management, Vol. 19 No. 1, pp. 6-21.

Olsson, M. and Hellsmark, H., (2012), "Effektutvärdering av Produktionslyftet: Fas1: 2007 - 2010”, Vinnova, Stockholm.

Parker, S. K. (2003), "Longitudinal effects of lean production on employee outcomes and the mediating role of work characteristics”, Journal of Applied Psychology, Vol. 88 No. 4, pp. 620-634.

Pink, D. H. (2010), Drive: The Surprising Truth about What Motivates Us, Canongate, New York.

Prater, E. and Ghosh, S. (2006), “A comparative model of firm size and the global operational dynamics of U.S. firms in Europe”, Journal of Operations Management, Vol. 24 No. 5, pp. 511-529. 
Rahman, M. N. A. and Tannock, J. D. T. (2005), “TQM best practices: Experiences of Malaysian SMEs”, Total Quality Management \& Business Excellence, Vol. 16 No. 4, pp. 491-503.

Ramböll, (2009), “Utvärdering Produktionslyftet”, Tillväxtverket, Stockholm.

Robinson, A. G. and Schroeder, D. M. (2006), Ideas Are Free: How the Idea Revolution is Liberating People and Transforming Organizations, Berrett-Koehler Publishers, San Francisco.

Ryan, C. and Moss, S. E. (2005), "Total quality management Implementation: The "core" strategy”, Academy of Strategic Management Journal, Vol. 4, pp. 61-76.

Salaheldin, S. I. (2009), "Critical success factors for TQM implementation and their impact on performance of SMEs”, International Journal of Productivity and Performance Management, Vol. 58 No. 3, pp. 215-237.

Sousa, R. and Voss, C. A. (2002), "Quality management re-visited: A reflective review and agenda for future research”, Journal of Operations Management, Vol. 20 No. 1, pp. 91-109.

Steiber, A. and Alänge, S. (2013), Diffusion of Organisational Innovations: Learning from Selected Programmes, Vinnova, Stockholm.

Struebing, L. and Klaus, L. A. (1997), “Small businesses thinking big”, Quality Progress, Vol. 30 No. 2, pp. 23-27.

Temtime, Z. T. (2003), "The moderating impacts of business planning and firm size on total quality management practices”, The TQM Magazine, Vol. 15 No. 1, pp. 52-60.

Turner, R., Ledwith, A. and Kelly, J. (2009), "Project management in small to medium-sized enterprises: A comparison between firms by size and industry”, International Journal of Managing Projects in Business, Vol. 2 No. 2, pp. 282-296.

Turner, R., Ledwith, A. and Kelly, J. (2010), "Project management in small to medium-sized enterprises: Matching processes to the nature of the firm”, International Journal of Project Management, Vol. 28 No. 8, pp. 744-755.

U.S. Census Bureau, (2015), "Number of Firms, Number of Establishments, Employment, and Annual Payroll by Enterprise Employment Size for the United States and States, Totals: 2012”, available at: http://www2.census.gov/econ/susb/data/2012/us_state_totals_2012.xls (accessed 28 January 2015).

van der Wiele, T. and Brown, A. (1998), "Venturing down the TQM path for SME's", International Small Business Journal, Vol. 16 No. 2, pp. 50-68.

Yusof, S. R. M. and Aspinwall, E. (2000), "A conceptual framework for TQM implementation for SMEs”, The TQM Magazine, Vol. 12 No. 1, pp. 31-37. 